\title{
Policy Initiative for Balance Regional Development and Growth
}

\author{
Rajeev Rana \\ Department of Economics, APB P.G. College, Augustmuni, India \\ Email: rajeevjeet@gmail.com
}

How to cite this paper: Rana, R. (2018) Policy Initiative for Balance Regional Development and Growth. Theoretical Economics Letters, 8, 3034-3045.

https://doi.org/10.4236/tel.2018.814188

Received: August 27, 2018

Accepted: October 21, 2018

Published: October 24, 2018

Copyright $\odot 2018$ by author and Scientific Research Publishing Inc. This work is licensed under the Creative Commons Attribution International License (CC BY 4.0).

http://creativecommons.org/licenses/by/4.0/

\begin{abstract}
The economics growth and development mostly coined together, and it was thought that growth itself led to development of the country but it was found that there are more dissimilarities than complementary. A higher growth will spontaneously lead development only when there is equitable distribution of resources and balancing regional development. But it did not happen in practices as high growth widen inequality and unequal distribution between the different groups of people in the societies as well between inter-state and intra-state to create regional imbalance, further as there is a transition period of the economy and urbanization took place it was experienced that regional imbalance widen in the term of class difference, gender discrimination (lower participation of women, as well alarming sex ratio), resources distribution, and per capital income. Further, the regional economic disparities create more inequality between savings, investment, and had interconnected map over the vicious cycle of corruption, demographic challenges, influencing chronic \& infectious diseases, illicit trade, migration, food insecurity, and governance failures. The paper is addressing those various issues and thrust area of policy initiatives to present the causes of regional imbalance and growth as well the policy initiative for inclusive development.
\end{abstract}

\section{Keywords}

Economic Development, Regional Imbalance, Vicious Cycle, Policy Initiative

\section{Introduction}

To begin with economic growth and development are often associated to each other and it was think that a sound growth will push development to all sector itself, which mean growth become vital for economic development. A high growth will increase per capital income and further push development of econ- 
omy will bring harmony in the society in the term of resource distribution, wealth, and income, which create equity in the society and its ability to break vicious cycle of poverty, demographic and ability to reduce disparity. So, in this term, economic growth becomes not only essential but vital to achieve the growth and balance development including contribution by all sectors. However, there is conceptual difference in both term explaining growth and development. Essentially, in the net term the growth lies with increment in the productive activities in the term of Gross Domestic Product (GDP), whereas, development is the other issue and mainly associated with the equity.

To address both Growth vs. Development need, special address in the term of the viability of the issues, which one of the most important in the term to achieved socio-economic objective often become elusive and standard argument have been given on time-to-time. On the basis of definition, there is need to address the concept of Economic growth we should think much about the productivity and resources generation for the whole community. As well as need of providing other factors like infrastructure, a better transport, decent living of standard, sanitation, clean drinking water, energy and others become the part of Economic Development. To explain that which are the essential in both of them is elusive, and a high economic growth may have low level of living of standard as well high development may have low growth rate but to have both are essential for inclusive growth.

However, most of the development theories suggest that as economic transition occurred, the economy faces more severe problem of disparities as they face sever vicious cycle of poverty and inequality [1], and stuck to lower-level equilibrium trap particularly for developing nations (see figure), from both supply and demand sides and reflect to sluggishness and backwardness in the economic productivity. Further, the concept of growth has been defined with keeping the objective of balance growth path [2] [3] and unbalance growth path [4] to attain pace of growth from the sluggish and backward economic structure.

\section{Regional Growth: An Issue}

There huge literature which suggest that as the economy caught with high growth rate and development starts initially, more inequality increases with greater rate and then falls [5], and as the economy begun with development and growth, they have different phase i.e. Traditional society $\rightarrow$ pre-condition of take off $\rightarrow$ take off stage $\rightarrow$ drive to maturity $\rightarrow$ high mass consumption stage [6], these are the common phase as the economy fall in different trap as growth and development process undergo. Due to economic backwardness and acute shortage of resources mobilization at every stage of growth, economies face severe bottleneck as well unequal distribution of resources. So, growth can be completely different for the development objective particularly defining the deployment is difficult but in simple term development is more associated with well-being of society i.e. economic development in complete sense include much broader variable 
as suggested [7] in the following equation:

$$
D=f(G D P)+I+I^{*}+G o+P R
$$

where: $I$, denotes physical and social infrastructure, $I^{*}$-Innovation, Go-governance and PR-poverty reduction.

While, the undergoing need of present and lot of discussion went for inclusive development where each and individual get the share of benefit from the growth, the above equation seems little conservative and I would like to emphasis to add on additional variable as it has been prove in many literature, working institutions, as well for planners that development should be plan keeping the Equity as a main factor in the mind, as mention in many books, discussion and standard argument in ancient and modern literature (Niti, Naya ${ }^{1}$ ) [8], As Pareto optimality $^{2}$ suggest that equity can be attain by making further redistribution, if there is possibilities of further redistribution in the society and making further redistribution if there is improvement of any one individuals utility or satisfaction without changing the satisfaction of other person redistribution will be equitable and argue that definition of development cannot be complete until it include concept of equity (i.e. equal distribution of resources), and equity is more associate with Sustainability means substantiality of resources as the whole theory of Economics talk about means and scare. And in the era of growing need and exploitation of resources as they are means of ends. So, in the era of deepening of globalization and excessive exploitation of resources $I$ would like to introduce one more variable in the above equation in which a new equation become:

$$
D=f(G D P)+I+I^{*}+G o+P R+E S
$$

where, $E S$ stand for Equity and Sustainable distribution of resources

Now, this reveals the clear explanation of economic development as the development is more associated with the idea of equity and justice (Sen.), as well current need to make development which is more sustainable manner.

\section{Development: As a Challenge}

In the developing countries where there is acute shortage of resources in the term of underutilization or inefficiency due to poor human capital, backward technology, push economics into low level development path and due to scare resources like raw-material, and mass heterogeneity in the population create enormous problem in many ways as the process of growth starts disparities spread within the society in term of unequal distribution of income and wealth, which further create problem of class division (Karl Marx) [9], as well inequality in the saving and investment which suddenly harm regional growth due to that consumption is made by rich class and poor class not able to consume due to lower wages rate or per capital income, as the economy grows or national in${ }^{1}$ Niti and Naya: explain under Manu Script of Indian legal theorist and have been accepted as a Global Perspective on the Rule of Law.

${ }^{2}$ For Pareto optimality see first and second welfare fundamental theorem and condition of Pareto improvement. Amratya Sen book on The Idea of Justice, published at Harvard University Press. 
come increases inequality also increased in high rate [5], further pushing to the society at more vulnerable trap. Which results more hazardous problem and greater inequality and disparities not only in countries but as well in states, or at regional level which create sever problem of demographic challenges, black marketing, illegal trade, migration from poor states to rich states and unbalance growth push economy into the vicious cycle of poverty, food insecurity, unemployment and impose serious threat on its development.

Further, development which is mostly associated for the upliftment of well-being or welfare of the individuals/society get affected in the term of low living of standard, creating more slums area in the urban and no housing in the rural areas, and massive poverty as well as low literacy rate in both child and workforce in the society which further hurt productivity in the economy, and under productivity in the society create unequal share of wage rate of which lower class do not have physical access, economics access and financial access of resources in the society as well inability to access of food grain result of under-malnutrition, which adversely affect health disease and hazards, and continuous widespread in the whole area which not only affect the growth of labor but also for whole community, and pose other serious risk as one of the most important of raising alarming sex ratio between male and female pose socio-economic threats in the whole community.

All this problem are inter-connected and attached form each other in the term of vicious demographic challenges beside these common socio-economic problem there are several other problem which impose serious threat in the growth and development: as food shortage, continues rising prices of agriculture good in the market pose question of food security, low fertility in soil, pollution, and most important to tackle climate change and environmental problem remain main objectives of current growing needs.

Despite growing social challenges there are other economics need of institutional factors which must also addressed those factor are equally inevitable for the economic growth and development and due to ignorance the risk is so high and usually involved market failure or distortion of prices and markets, to address those economic factors they are followings:

\subsection{Externalities}

Externalities in economics are used in term of either Positive and negative. Sometime it refer with reference of costs, in term of negative externalities or in the way of positive externalities, due to which goods do not reflected in free market prices and have some spillover effects. Externalities seem very important agent in economic theory for government to adopt planning that "internalize" an externality, which imposed costs and benefits on others who are not responsible for initiating the effect. The basic example of negative externalities are pollution, gases, produce by industries which have severe contribution in economic growth. Whereas, a good example of positive externalities are development of street light, education, good infrastructure to boost the sustainable economic 
development.

Externalities are vital and require specific attention for tackle the issues of externalities as due to high negative externalities involved directly hurt to the obtaining desired social result, to address externalities become critical to get fruitful results. There are various issues where externalities issues should be resolved with the help of introducing market system, (to address issues of providing prices of those goods which are non-tradable), well define property rights (particularly, in the case of open access resources), or imposing taxes to curb the cost of pollution and compensating to the society while charging cost of pollution from the industrialist.

\subsection{Governance Failure}

The impact of negative externalities is on market failure which means market is not able to deliver the desired outcome or do not reflect true market price. Due to which lack of true price we do not have efficiency in allocation, production and distribution of resource. When market become undesirable or not able to provide efficiency it has sever effect on planning and controlling market mechanism. Consequently, government intervention to sought market failure is not achieved. Government failure is an attempt where government is anticipating to correct the market failure due to inefficiency which have spillover effect on misallocation of resource.

In the economic jargon "government failure" means that government is not able to achieved best outcome called "pareto efficiency" and the objective to achieved Pareto optimality (optimum welfare) [10] is not desirable in the despite of efforts of government. That is due to distortion in government policy and market mechanisms like taxes (that effect goods and services price due to imposing higher taxes, as increasing prices artificially distort the efficient market operation), and moral hazard (moral hazard is a problem when government pass on some benefits to the society and person known that government will provide such helps they behave irrationally e.g. if government is subsidizing free insurance to the driver the impact of this people drive badly as they know government have insured their lives.

At present scenario the concept of governance failure become hot issues as there are inefficiency to the huge welfare programming running by government to achieve desired outcome of socio-economic programs due to highly corruption involved in the implementation phase and inability to produce desired results.

\subsection{Contagion Effect or Spillover Effect}

Contagion is a transmitting disease which transmitted very fast form one place to other place, contagion may have good effect as well bad effects and spread very fast to the in the neighbor, like a good policy result attract policymakers to frame some more good welfare programs which further push the development of 
the society, while bad or ineffective welfare programs will discourage to the policy makers at the time of its framework and implementation period. The effect of good policy in one state will encourage running some development plans in other states are spillover effects.

\subsection{Desired Planning to Tackle the Issues and Growing Challenges}

A different type of Planning in India have been suggest with different approach like top-to-bottom and vice versa, but special efforts was made for the planning should be from the village level [8], within the grass root level and more emphasis and autonomy should be given to the states and local authority called "people plan" by M. M. Roy, and our planner give more focus on state driven growth as the state can be main pillar of economic growth and development, keeping the objective of participation of Local body the government took imitative to give power to Local authority and decentralization of the planning within the ambit of local society for which government took some constitutional amendment which are $73^{\text {rd }}$ and $74^{\text {th }}$ constitutional amendment which deliver the power of Regional planning for faster economic growth and development. As the regional planning are define by different persons as it is the kind of framework for national development scheme of which best suited to regional need of its population (zweig), and (Tinbergen). Regional planning become the best suited planning for the balance growth and development due to the rationality in different group or need based planning which are different from geographic regions.

Further, in the growing need the objective of present planning should be more equitable of distribution of resource and bring inclusive growth i.e. inclusion of all sectors and areas where every individual participation bring the benefit of growth, which must address to balance growth path for the regional development, and required wider participation of society as well as different group of people to share resources benefit at local level and better management of domestic resources. For this new regional planning concept have been introduced which including wide coverage of local people and giving more autonomy and flexibility in the hand of those to address their problem more elaborately and find appropriate solution as best suited them which include participatory planning method or Participatory Learning Activities [11], which will bring more efficacious in planning to achieved desired goal and socio-economic outcomes as targeted for the equitable growth and development within the grass root level, and to break the vicious cycle of demographic challenges as well as to address more effectively those others issues which need more address such as environmental issues and forest conversation, sustainability of resources etc.

From the above discussion it is clear that there different aspects which affect economic growth and development of the country, to provide a sustainable development government should focused on those issue, while addressing issues of externalities in the economy government need to define property rights clearly, 
there should not be asymmetry of information, no misallocation of resource and efficiency on distribution of resource. The government should achieve Pareto-optimality condition to overall sustainable development.

\section{Policy Initiative for Regional Balance Growth and Development}

It is elusive to explain a what sort of kind of policy required for the balance regional growth and development, to define clearly which policy require and how policy makers should frame policies, what are those factors which planner need to address not only difficult but complex in real world.

While, to formulate policy one need to understand s political economy approach of the particular policy and its desired objectives, i.e. targeting growth trajectory, understanding the community sentiments, resource allocation and distribution in the society, and society's cultural and religious aspects. Sometimes, society believed on some rituals, on which they try to maximize their private outcome then the socially desired outcomes, to which they act's as irrational behavior to achieved rational goals. Due to which a variety of specialization required to understand the policy framework and problem of rationalization or behavioral sciences [12].

To address that what should be policy initiatives for balance regional growth firstly, one must understand the rationality of individual in the society as game theory tell us that how the game model address issue of rationality and what game individual plays in the society [13], it become vital for policy framework and to analysis of welfare in the society [14], more has been done under strategic analysis how extensive game theory is appropriate for the planning in the term of rationality [15], become inevitable for planning in the current scenario, a study of irrationality in extensive game theory show the rationality of individual agent as well as how rationally they behave themselves! as rational agent even they behave irrational, and shows that No coordination exist in the long run although it seems that initially they might cooperate to each other but in the long run [16], a standard solution of Prisoner's Dilemma [17] shows agent behavior that there is Non-cooperation exist between among the agents.

\section{Spillover Effects}

Equity and Efficiency Tradeoff between among the states, how states achieved lower level of growth and development if they do not coordinate with among them because of rational behavior and nature of every rational behavior is Nash Equilibrium, which lies when both states A and B end up with Non Coordination Solution at (Low, Low), equity and efficiency tradeoff. They do not cooperate and growing much faster on one state have some spillover effect to neighbor states or regional areas as if neighbor states grow at speedy and development process starts with high growth of rate what happen. The coordination game basically proposed by Nash is a classic game of two payers, where two strategies, 
and given payoff matrix as shown in Table 1 . If the two payers coordinate, by adopting strategies to coordinate and choose $(\mathrm{C}, \mathrm{C})$ then will receive the highest payoff, i.e. (HIGH, HIGH), but if players opted any other strategy from (C, C) to (C, NC) etc. There is still a Nash equilibrium. However, each players will received less than optimal payoffs and has no incentive to change the strategy due to reduction in payoff.

The above Nash Equilibrium solution is also possible for the political parties in the democratic government where there are two parties one, who is winning and Leader, and another is party in opposing called rival, as thing very optimistic and further assumed that party in majority is more liberal and have plan for making more reforms for economy to push towards development they required support of oppositions for the majority, as opposition know that the program is introduce make lot of reforms and good governance will be establish, but due to its one political stability, they do not cooperate and here again the situation end up with low reforms and development which make clear, how rationality in planning become important and need special address which required extensive game theoretical framework model and strategic analysis [18].

In such situation there might be a spillover effect as some state become forward in term of development activities and other are backwards, where in the lower development states people might to shift in the high development areas, as problem of migration occurred in the higher development state, and it attract society of lower development states due to which excessive migration took place which slow down the speed of development in the good states and both states end up with experience of low equity and efficiency.

\section{Endogeneity in Variable and Optimality}

To having better policy initiative one need to clearly define the applicability of variable who effect the policy widely, i.e. it's should be clearly define that which variable should be take endogenous or exogenous variable or custom who affect policy in many ways like variable who affect our policy internally should be consider important and otherwise if not affect our policy [19] to work on macroeconomics model it is difficult to address rationality or intuition of the individual and because these intuitions and variable are not covered by most of the model due to which policy become flaws and do not solve the problem of optimization as explain by Lucas critique Lucas [20].

Table 1. The payoffs matrix of Nash equilibrium.

\begin{tabular}{ccc}
\hline & \multicolumn{2}{c}{ Player's B' } \\
\hline $\begin{array}{c}\text { Coordinate } \\
\text { Player's } A \text { ' }\end{array}$ & High, High & Non Coordinate \\
\hline Non Coordinate & Low, High & High, Low \\
& & Low, Low
\end{tabular}




\section{Resolving Issues of Government Failure}

Tackling the issues of Governance failure: become essential that how governance failure should be prevent, to tackle failure of governance and build strong mechanisms to stop illegal practices, such as corruption, malpractices, black marketing, illegal trade, money laundering etc. can be tackle effectively when we have strong network and institutional support to identify and continuous monitoring and evaluation management and better technological updated mechanisms programs for building more transparent system as government in India has implemented a programs of Addhar or UAID [21], which have following three core objective:

> To provide accessible identification that can be used for entitlement

$>$ To prevent distribution of efforts and leakage existing in the current systems

To enable services and application that requires a verifiable unique ID

These will not only tackle issues but will provide clean distribution to the targeted person the symbiotic network shown in Figure 1. Which will enhancing efficacious by providing bio-metric identity numbers and strongly prevention form illegal activities as duplication is not possible as well the befits will received by every class in the society which bring equity and inclusiveness.

Another areas of the policy initiative which need to address is providing values of non-markets good i.e. those goods which are not maketized means value cannot assigned in the market it become difficult due to lack of market for those goods like cost of clean air, to set the price for pollutions, due to its implicit nature that they do not include social cost and marginal private benefit is more than social marginal befits, to assigning value of non-marketable good is possible by assigning value on the basis of some non-markets good on the basis of market goods, or on the basis of Shadow pricing is become important where price should be decided on the basis of akin goods or some other cost-benefit approach, it will helps to the social planner to plan more appropriately and address

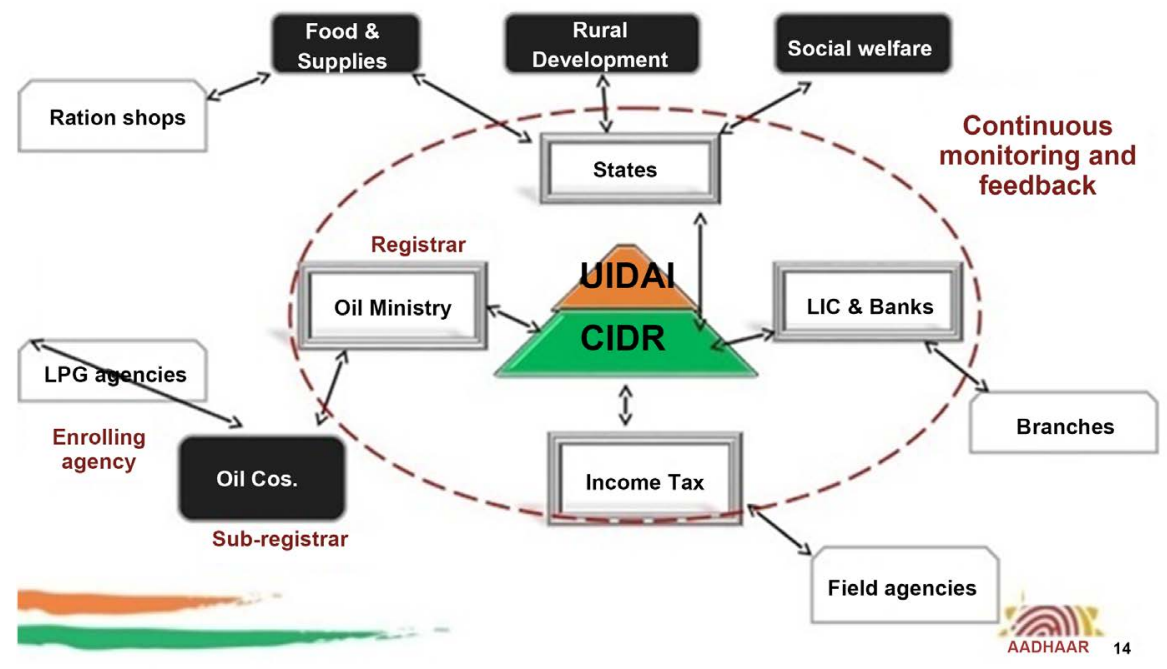

Source: uidai.gov.in

Figure 1. The UAID symbiotic network. 
those variable which are associated with social welfare or high development agenda.

To obtain optimality in the distribution of resources we must think about providing public good, one side where public goods provide distortion in the market and usually lead to market failure [22], which can be restored via providing Pareto efficiency under first fundamental theorem which used that every competitive activity in the economy bring efficiency and restore market failure, due to externalities, natural monopolies, and public goods which need a attention by government to correct these market failures.

As living today world which have enormous challenges to providing inclusive growth and development with keeping the sustainability of resources for the future become more elusive and to planning required lot of SWOT Analysis for the present need and threats, SWOT Analysis are more helpful to define the areas of priorities, at which type of good to be produced and at what cost, will it have greater effect In the development in the long-run are the some questions which need address as to merely see target the growth rate are not a solution and cost-benefit analysis need to be address when good have greater impact on environmental cost and nature of public goods, as well as areas of open access resources which need high protection as open resources are the issues which need to address specifically due to its nature of no one have exclusive right of using open resources like fishing in the open sea, one party cannot exclude to by fishing to other party, the best solution for open resource problem Ronald Coase [23] has given solution for open resources problem which may be more fruit full for the planner for policy framework.

\section{Summary and Conclusion}

To accelerate the pace of regional growth and development, it is important to understand what are the perquisites for local communities and societies, and it is difficult to define what should be done for the balance growth and development and include brainstorming! By experts and policy frameworks, as per my view I would focus more on those issues which need special attention and for effective planning need to address all area due to their growing need and problems. To answer the question what kind of policy required I would firstly said that we should include participation of local community in the term of collective efforts or collective bargaining to bring good result and to understand the joint responsibility of society by establishing Joint Responsibility Management involving local community based approach for inclusive regional development.

For effective policy implementation we should include the Local community and need to run awareness programs which is priority as it seems that people usually are not aware with the government programs running for welfare and development. So, awareness can be spread taking help of NGO's, Institutional setup, call-centers, and awareness programs run by village Panchayat, Ghram-shaba and government office including schools and colleges, targeting 
local Newspapers government through which government can communicate directly to the local community and reduce leakages as well as more effective to tackle issues of migration in the systems which may bring fruitful result for the whole regional development.

The other impressive initiatives of the government have been taken in its policy to curb the issue of corruption, and black marketing by introducing Adhaar/UIDAI based unique identification identity, that will strongly tackle the issues of effective monitoring and corruption due to which planner not able to attained desired social goods or building social assets, where one side it will reduce leakage in the systems and other side help to bring more facilities with limit time and efforts as beneficiaries will able to access all information related to health, utility, education, employment and social befit programs by using biometric number provided by UIDAI.

Finally, an effective policy implementation needs a stable government and mechanism system, often having good instrument does not give desired fruit due to lack of willingness as well political instability. So, to choose stable government was one of the difficult tasks as defined by Kenneth Arrow (See, Arrow impossibility theorem) that how government come to majority via voting method, so better government will not only bring sound growth but also inclusive development.

\section{Conflicts of Interest}

The authors declare no conflicts of interest regarding the publication of this paper.

\section{References}

[1] Leibenstein, H. (1957) Economic Backwardness and Economic Growth. Wiley, New York.

[2] Haberler, G. and Stern, R.M. (1961) Equilibrium and Growth in World Economy: Economic Essays by Ragnar Nurkse. Harvard University Press, Cambridge.

[3] Lewis, W.A. (1955) The Theory of Economics Growth. London.

[4] Alberto, H. (1958) The Strategy Economic Development. Yale University Press, New Haven.

[5] Kuznets, S. (1955) Economic Growth and Income Inequality. American Economic Review, 45, 1-28.

[6] Rostow, W. (1991) The Stages of Economic Growth: A Non-Communist Manifesto (pp. 59-72). Cambridge University Press, Cambridge.

[7] Mahtaney, P. (2007) India, China and Globalization. Palgrave Macmillan, London.

[8] Sen, A. (2009) The Idea of Justices. First Harvard University Press paperback ed.

[9] Llorente, R. (2006) Analytical Marxism and the Division of Labor. Science \& Society, 70, 232-251. https://doi.org/10.1521/siso.2006.70.2.232

[10] Brownstein, B.P. (1980) Pareto Optimality, External Benefits and Public Goods: A Subjectivist Approach. University of Baltimore, Baltimore.

[11] Goldman, I. and Abbot, J. (2004) PLA49: Decentralization and Community-Based Planning, IIED: 9312IIED. 
[12] Dunbar, G., Wang, R.Q. and Wang, X.T. (2003) Rationalizing Irrational Beliefs. Economics Department, Queen's University Kingston, Ontario.

[13] Basu, K., Becchetti, L. and Stanca, L. (2011) Experiments with the Traveler's Dilemma: Welfare, Strategic Choice and Implicit Collusion. Social Choice and Welfare, 37, 575.

[14] Sen, A. (1999) Resources, Values and Development. Oxford University Press, Oxford.

[15] Basu, K. (1986) Strategic Irrationality in Extensive Games. Delhi School of Economics, Delhi.

[16] David, K., Paul, M., John, R. and Wilson (1982) Rational Cooperation in the Finitely Repeated Prisoners' Dilemma. Journal of Economics Theory, 27. Issue 2.

[17] Wolpert, D.H., Jamison, J., Newth, D and Harre, M. (2009) The Optimality of Non-Rational Behavior in Single-Shot Games.

[18] Dunbar, G., Wang, R.Q. and Wang, X.T. (2016) Rationalizing Irrational Beliefs. Theoretical Economics Letters, 6, 1219-1229. https://doi.org/10.4236/tel.2016.66115

[19] Basu, K. and Nolen, P. (2006) Vulnerability, Unemployment and Poverty: A New Class of Distribution and Sensitive Measures, Its Axiomatic Properties and Applications. In: Studies in Choice and Welfare, 237-258. https://doi.org/10.1007/978-3-540-79832-3_13

[20] Tesfatsion, L. (2012) Notes on the Lucas Critique, Time Inconsistency, and Related Issues.

[21] http://www.uidai.gov.in/

[22] Bator, F.M. (1958) The Anatomy of Market Failure. The Quarterly Journal of Economics, 72, 351-379. https://doi.org/10.2307/1882231

[23] Coase, R. (1960) The Problem of Social Cost. Journal of Law and Economics, 3, 1-44.

\section{Notes}

- Simon Kuznets, (1955) give Kuznets curve which measure Gini-coefficient of inequality and Income for the countries as a widening gap in the initial period of growth and development.

- Dr. Kaushik Basu currently Chief Economic Advisor to Government of India, and renowned Professor at Department of Economics cornel university, USA.

- A excerpt taken from Dr. Basu speech from National seminar at New Delhi on Feb. 2012, during he was addressing for policy initiatives for stability measures, and his work on Extensive game theory.

- Nash Equilibrium is the standard model under Game theory.

- Coase theorem given by Ronald Coase (1960), and contribution was made to defining property right for open access resources.

- Kenneth Arrow's Impossibility theorem includes mathematical result on "No voting method is fair", "Every ranked voting method is flawed", or “The only voting method that isn't flawed is a dictatorship. 